\title{
Socioeconomic Trends in Differential Mortality among Middle-Aged Males in Norway 1960-1990
}

\section{JENS-KRISTIAN BORGAN}

\author{
Adviser \\ Statistics Norway \\ Oslo, Norway
}

\begin{abstract}
This study is based on data from three censuses $(1960,1979$, and 1980) linked to the cause of death statistics kept during a 10-year follow-up period subsequent to each census. Linkages have been made for each individual male aged 30-64 years at the time of the census, based on their Norwegian national personal identification numbers. Socioeconomic status categories are specified according to the Norwegian classification of socioeconomic status. The 10-year post-census follow-up periods have each been divided into two five-year periods, and mortality has been calculated for both, based on the subjects' socioeconomic status at the outset of the 10-year period.

The study showed a decrease in mortality for all socioeconomic status categories. However, the decrease was far more pronounced among mean-level and higher-level salaried employees than among unskilled workers, farmers and fishermen. An even larger socioeconomic gap appeared between the rates of mortality due to cardiovascular disease. There are indications that the gaps may be healthrelated, since workers' mortality rate increased from the first to the second five-year period following a census, while the same pattern was not found for salaried employees.
\end{abstract}

Keywords: socioeconomic status, mortality, causes of death, males, Norway

\section{Introduction and background}

Norway's first study of mortality by occupation was published in 1974 (Tønnesen 1974). It linked mortality data for 1961-1964 to census data from 1960. Cause of death was not included in the study. In the same way, Haldorsen and Glattre (1976), Kristofersen (1979), and Borgan and Kristofersen (1986) linked mortality data to the 1970 census.

In 1984 Statistics Norway published a new standard classification of socioeconomic status (Statistics Norway 1984). Based on this classification, and including mortality by occupation, Borgan and Kristofersen presented data on mortality by socioeconomic group in 1970-1980. Dahl and Kjærsgaard (1993) used mortality data from 1960$1965,1970-1975$, and 1980-1985, based on the same socioeconomic status classification system. 
Numerous other industrialized countries have indicated their interest in this study of socioeconomic trends in differential mortality. From 1979 to 1989, CICRED (Committee for International Cooperation in National Research in Demography) in Paris organized five meetings of a network on Socio-Economic Differential Mortality in Industrialized Societies.

Since 1993, the EU's Concerted Action Programme "Socioeconomic inequalities in morbidity and mortality in Europe: a comparative study" has been led by Erasmus University in Rotterdam. A number of European countries cooperate on this project.

\section{Data and methodology}

This study is based on three different sets of data. The first set, mortality data from 1 November 1960-31 October 1970, is linked to the 1960 census by the individuals' national identification numbers. The second data set, mortality data from 1 November 1970 to 31 October 1980 , is linked to the 1970 census, and the final set, mortality data from 1 November 1980 to 31 October 1990, is linked to the 1980 census. Each individual has been monitored from the date of census until migration from Norway, death, or to the end of the period of observation. The period of observation has been calculated for each individual in years, divided to two decimal places. Each 10-year period following a census has been divided into two five-year periods.

Due to missing identification numbers, about 2 percent of the population in the 1960 census have been omitted from the study. The cause of death was listed as unknown for about 3 percent of all the individuals in question from 1960 to 1966.

The results of the study are to some extent stated as age-specific mortality rates and to some extent as standardized mortality ratios (SMR). The figures refer to all members of the male population in the 30-64 age bracket at the beginning of the five-year periods.

As mentioned earlier, the population has been divided into socioeconomic groups according to the Norwegian Standard Classification of Socioeconomic Status. This standard classifies an individual as economically active if he or she had at least 500 paid working hours over the past year. As the 1960 census contained no information on working hours, individuals were classified as economically active if their main source of livelihood was their own income.

\section{Trends in economic activity and socioeconomic status}

In 1960, nearly 97 percent of the male population aged 30-64 were classified as economically active, compared with only 22 percent of the female population in the same age group. By 1970, the percentage of occupationally active males had decreased to 92 percent and, by 1980 , to 87.5 percent. In contrast, female occupational activity had increased to 39 percent by 1970 and 53 percent by 1980 . Table 1 shows distribution by socioeconomic status of the individuals included in the three censuses.

The increase in the number of male pensioners was mainly the result of the introduction of the National Insurance System in 1967. Most people classified as "other persons not economically active" had from 100 to 500 hours of paid employment during the preceding 12 months.

From 1960 to 1980 , there was a decrease in the number of male unskilled workers, farmers, and fishermen, while both mean- and higher-level salaried employees increased. 
T a b le 1. Population aged 30-64 years old according to socioeconomic status in 1960, 1970, and 1980. Percent

\begin{tabular}{lrrrrrrr} 
& \multicolumn{3}{c}{ Males } & \multicolumn{3}{c}{ Females } \\
Socioeconomic status & 1960 & 1970 & 1980 & 1960 & 1970 & 1980 \\
All & 100.0 & 100.0 & 100.0 & 100.0 & 100.0 & 100.0 \\
Economically active & 96.7 & 92.0 & 87.5 & 21.7 & 38.9 & 52.8 \\
$\quad$ Unskilled workers & 35.9 & 32.6 & 24.0 & 4.5 & 8.4 & 8.7 \\
$\quad$ Skilled workers & 12.9 & 12.2 & 13.6 & 1.1 & 0.7 & 1.1 \\
Salaried employees, lower level & 4.0 & 3.8 & 3.3 & 8.1 & 13.0 & 20.2 \\
Salaried employees, mean level & 15.3 & 19.1 & 24.2 & 5.3 & 7.1 & 14.4 \\
$\quad$ Salaried employees, higher level & 3.6 & 4.9 & 8.3 & 0.5 & 0.8 & 2.4 \\
Farmers and fishermen & 15.3 & 10.3 & 6.8 & 0.8 & 6.4 & 3.4 \\
Other self-employed & 9.6 & 9.0 & 7.0 & 1.5 & 2.4 & 2.3 \\
Economically inactive & 3.3 & 8.0 & 12.5 & 78.3 & 61.1 & 47.2 \\
$\quad$ Students and pupils & 0.2 & 0.3 & 0.3 & 0.1 & 0.5 & 0.7 \\
Pensioners & 2.2 & 6.7 & 6.9 & 3.9 & 9.6 & 10.8 \\
Home workers & 0.0 & 0.1 & 2.2 & 70.1 & 50.2 & 26.0 \\
$\quad$ Other persons not economically active & 1.0 & 0.9 & 3.0 & 4.2 & 0.8 & 9.6
\end{tabular}

Family members with no fixed wage are excluded from the economically active in 1960, but included in 1970 and 1980

Owing to the weakness of the connection between women's economic activity and socioeconomic status, especially in the earlier periods, subsequent discussions will be based on the mortality rates for groups of males categorized by socioeconomic status.

\section{Main results}

Table 2 illustrates the age-standardized mortality rates (SMR) by socioeconomic status for males 30-64 years of age at the beginning of each of the six five-year periods. For the first three periods, socioeconomic status was registered at the beginning of the period, while for the last three periods, socioeconomic status was registered five years prior to the beginning of the period. The standard population comprised all males aged 30-64 in the 1960 census.

Table 2 indicates that the total mortality for males aged 30-64 (at the beginning of the five-year period) increased 5 percent during the first five years of observation,

T a b le 2. Age-standardized mortality according to socioeconomic status for males aged 30-64 years.

$\begin{array}{lrrrrrr}\text { Socioeconomic status } & 1960- & 1970- & 1980- & 1965- & 1975- & 1985- \\ & 1965 & 1975 & 1985 & 1970 & 1980 & 1990 \\ \text { All } & 100 & 102 & 95 & 105 & 100 & 92 \\ \text { Economically active } & 92 & 84 & 72 & 101 & 91 & 78 \\ \quad \text { Unskilled workers } & 93 & 88 & 80 & 106 & 99 & 92 \\ \text { Skilled workers } & 102 & 87 & 75 & 112 & 97 & 80 \\ \text { Salaried employees, lower level } & 114 & 97 & 89 & 107 & 98 & 95 \\ \text { Salaried employees, mean level } & 99 & 85 & 67 & 104 & 84 & 69 \\ \text { Salaried employees, higher level } & 83 & 65 & 55 & 87 & 66 & 53 \\ \text { Farmers and fishermen } & 70 & 67 & 64 & 79 & 75 & 71 \\ \text { Other self employed } & 104 & 91 & 76 & 107 & 96 & 79 \\ \text { Economically inactive } & 240 & 243 & 196 & 242 & 220 & 195\end{array}$


then decreased to a level 8 percent below the level of the early 1960 s over the next 20 years.

Due to health-related selection, a stronger decrease in mortality was noted among economically active males as a whole, paralleling the decrease in their level of economic activity. From the early 1960 s to the early 1980 s, the mortality rate of economically active males decreased by more than 20 percent, compared with 5 percent for males as a whole, independent of economic activity.

All socioeconomic status categories experienced a decline in mortality from the early 1960 s to the early 1980 s, and from the late 1960 s to the late 1980 s. However, the decline in the mortality curves varied considerably among the different socioeconomic categories.

Mortality rates among farmers and fishermen decreased less than 10 percent from the early 1960 s to the early 1980 s, while they fell 30 to 40 percent for both mean- and higher-level salaried employees. During the same period, unskilled and skilled workers experienced decreases in mortality of 14 and 26 percent, respectively.

In the early $1960 \mathrm{~s}$, farmers and fishermen experienced much lower mortality rates than all other socioeconomic status groups (SMR $=70)$. In contrast, lower-level salaried employees experienced more than a 60 percent rise in their mortality rate $(\mathrm{SMR}=114)$. Higher-level salaried employees experienced a 20 percent higher mortality rate than farmers and fishermen.

Owing to unequal variations in mortality rates among different socioeconomic status groups, higher-level salaried employees experienced their lowest level of mortality 20 years later $(S M R=55)$, when it reached a level 14 percent lower than that of farmers and fishermen.

Table 3 gives figures similar to those in Table 2 for mortality caused by cardiovascular disease. This cause of death exhibits the same pattern as the overall mortality rate, although there is more variation. Lower-level salaried employees experienced a higher rate of mortality due to cardiovascular disease, mainly due to health-related selection. Mean- and higher-level salaried employees experienced a far more pronounced decrease in mortality from these causes than unskilled workers and farmers and fishermen. From the early 1960 s to the early 1980 s, the decrease was 35 percent or more for mean- and higher-level salaried employees, compared with 7 percent for unskilled workers and 5 percent for farmers and fishermen.

Table 4 provides an overview of age-standardized cancer-related mortality in various socioeconomic groups. While a significant decrease in cardiovascular mortality was experienced in the late $1960 \mathrm{~s}$, trends in cancer-related mortality increased slight-

$\mathrm{T}$ a b l e 3. Age-standardized mortality according to socioeconomic status for males aged 30-64 years. Cardiovascular diseases.

Socioeconomic status

All

Economically active

Unskilled workers

Skilled workers

Salaried employees, lower level

Salaried employees, mean level

Salaried employees, higher level

Farmers and fishermen

Other self employed

Economically inactive

$\begin{array}{rrrrrr}1960- & 1970- & 1980- & 1965- & 1975- & 1985- \\ 1965 & 1975 & 1985 & 1970 & 1980 & 1990 \\ 100 & 108 & 96 & 111 & 103 & 89 \\ 92 & 89 & 75 & 108 & 94 & 77 \\ 85 & 88 & 79 & 107 & 98 & 89 \\ 107 & 94 & 79 & 126 & 108 & 80 \\ 137 & 105 & 97 & 128 & 101 & 96 \\ 111 & 97 & 73 & 122 & 92 & 69 \\ 92 & 73 & 58 & 99 & 71 & 51 \\ 65 & 66 & 62 & 80 & 77 & 69 \\ 116 & 102 & 80 & 120 & 97 & 76 \\ 216 & 244 & 182 & 225 & 208 & 179\end{array}$


$\mathrm{T}$ a b l e 4. Age-standardized mortality according to socioeconomic status for males aged 30-64 years. Cancer.

$\begin{array}{lrrrrrr}\text { Socioeconomic status } & 1960- & 1970- & 1980- & 1965- & 1975- & 1985- \\ & 1965 & 1975 & 1985 & 1970 & 1980 & 1990 \\ \text { All } & 100 & 98 & 104 & 99 & 101 & 104 \\ \text { Economically active } & 95 & 89 & 88 & 98 & 98 & 97 \\ \quad \text { Unskilled workers } & 95 & 94 & 99 & 102 & 106 & 110 \\ \text { Skilled workers } & 112 & 98 & 92 & 113 & 102 & 101 \\ \text { Salaried employees, lower level } & 109 & 102 & 94 & 108 & 104 & 108 \\ \text { Salaried employees, mean level } & 101 & 90 & 83 & 93 & 94 & 91 \\ \text { Salaried employees, higher level } & 85 & 67 & 73 & 95 & 74 & 74 \\ \text { Farmers and fishermen } & 75 & 67 & 72 & 78 & 76 & 79 \\ \text { Other self employed } & 103 & 91 & 89 & 104 & 107 & 104 \\ \text { Economically inactive } & 240 & 167 & 170 & 151 & 143 & 155\end{array}$

ly during the same period. Here, too, more favorable trends were observed for salaried employees than for unskilled workers and farmers and fishermen.

Prior to 1980 , unskilled workers experienced far higher accident-related mortality rate than other socioeconomic groups, but a considerable decrease has been noted since then. This is primarily due to the substantial decline in occupation-related mortality since then. In the early 1960 s, nearly 40 percent of the accidental deaths among males aged 30-64 years were due to occupational accidents, compared with 20 percent 20 years later. Occupational accidents are more common among unskilled workers than among salaried employees.

T a b l e 5. Age-standardized mortality according to socioeconomic status for males aged 30-64 years. Accidents.

$\begin{array}{lrrrrrr}\text { Socioeconomic status } & 1960- & 1970- & 1980- & 1965- & 1975- & 1985- \\ & 1965 & 1975 & 1985 & 1970 & 1980 & 1990 \\ \text { All } & 100 & 112 & 87 & 108 & 97 & 83 \\ \text { Economically active } & 97 & 99 & 68 & 105 & 90 & 71 \\ \quad \text { Unskiled workers } & 129 & 126 & 8 & 138 & 16 & 90 \\ \text { Skilled workers } & 83 & 89 & 61 & 90 & 73 & 60 \\ \text { Salaried employees, lower level } & 57 & 77 & 66 & 60 & 65 & 72 \\ \text { Salaried employees, mean level } & 70 & 69 & 51 & 81 & 65 & 53 \\ \text { Salaried employees, higher level } & 33 & 55 & 35 & 59 & 46 & 38 \\ \text { Farmers and fishermen } & 96 & 112 & 96 & 100 & 104 & 111 \\ \text { Other self employed } & 80 & 90 & 77 & 85 & 96 & 75 \\ \text { Economically inactive } & 175 & 249 & 208 & 204 & 199 & 201\end{array}$

\section{More detailed comparisons between the mortality rate of unskilled workers and that of higher-level salaried employees.}

A more detailed comparison of mortality differentials will now be given for unskilled workers and higher-level salaried employees:

Table 6 compares the age-standardized mortality of unskilled workers to that of higher-level salaried employees for different causes of death in the five-year periods 1960-1965, 1970-1975 and 1980-1985.

During the first five-year period, unskilled workers experienced lower mortality 
T a b le 6. Proportion in age-standardized mortality, and 1980-1985.

$\begin{array}{lccc}\text { Cause of death } & 1960-1965 & 1970-1975 & 1980-1985 \\ \text { All causes } & 1.12 & 1.34 & 1.48 \\ \text { Cancer } & 1.12 & 1.40 & 1.35 \\ \text { Canser in respiratory system } & 1.30 & 1.37 & 2.29 \\ \text { Cardiovascular diseases } & 0.93 & 1.21 & 1.38 \\ \text { Ischemic heart diseases } & 0.89 & 1.28 & 1.45 \\ \text { Cerebrovascular diseases } & 1.03 & 1.25 & 1.03 \\ \text { Violent death } & 2.72 & 2.02 & 2.04 \\ \text { Accidents } & 3.85 & 2.30 & 2.51 \\ \text { Suicide } & 1.33 & 1.35 & 1.56\end{array}$

due to cardiovascular disease, while higher-level salaried employees subsequently experienced lower mortality rates from all causes of death.

Figure 1 shows the ratio of age-specific mortality for unskilled workers to that of higher-level salaried employees during the six periods of investigation. Figure 2 presents an overview of similar figures for mortality caused by cardiovascular disease.

Throughout the entire period of investigation, higher-level salaried employees experienced more favorable mortality trends than unskilled workers. The figures also indicate that the relative excess of mortality for unskilled workers was higher for overall mortality than for mortality caused by cardiovascular disease in the $1960 \mathrm{~s}$, while the reverse was true in the 1970 s and the 1980 s.

\section{Problems related to health-related selection}

Different patterns emerge for different socioeconomic groups if we compare mortality rates by socioeconomic status over a five-year period, i.e. by comparing the rate at the beginning of one period to the rate for the next five-year period, based on socioeconomic status five years prior to the beginning of the period.

Both unskilled and skilled workers experienced an increase in mortality from the first five-year period to the next. Compared with all males aged 30-64, mortality rose from 9 to 19 percent for unskilled workers and from 5 to 14 percent for skilled workers during the second five-year period. For salaried employees, however, the excess was almost negligible. The mortality rate for lower-level salaried employees even decreased from the first period to the second in the 1960 s.

The differences in the mortality pattern described above are ascribable to healthrelated selection. The mortality rate during the first five-year period subsequent to a census is related to actual socioeconomic status at the date of death or shortly before, while the second periods also include people who changed status (often due to retirement) several years before they died. These differences may stem from the fact that failing health frequently causes workers to give up their jobs earlier than salaried employees. Another explanation may be that there is an influx of workers with failing health into the category of lower-level salaried employees.

Differences in relative mortality between various socioeconomic status categories depend on the time lag between the registration of socioeconomic status and the date of death. This leads to a discussion regarding the amount of lag that reflects the most accurate picture of socioeconomic differences in mortality rates:

- the first period is more homogeneous, as the socioeconomic status is close to that at the date of death. 
F i g u re 1. Ratio of the age-specific mortality of unskilled workers to that of higher-level salaried employees in 1960-1990.
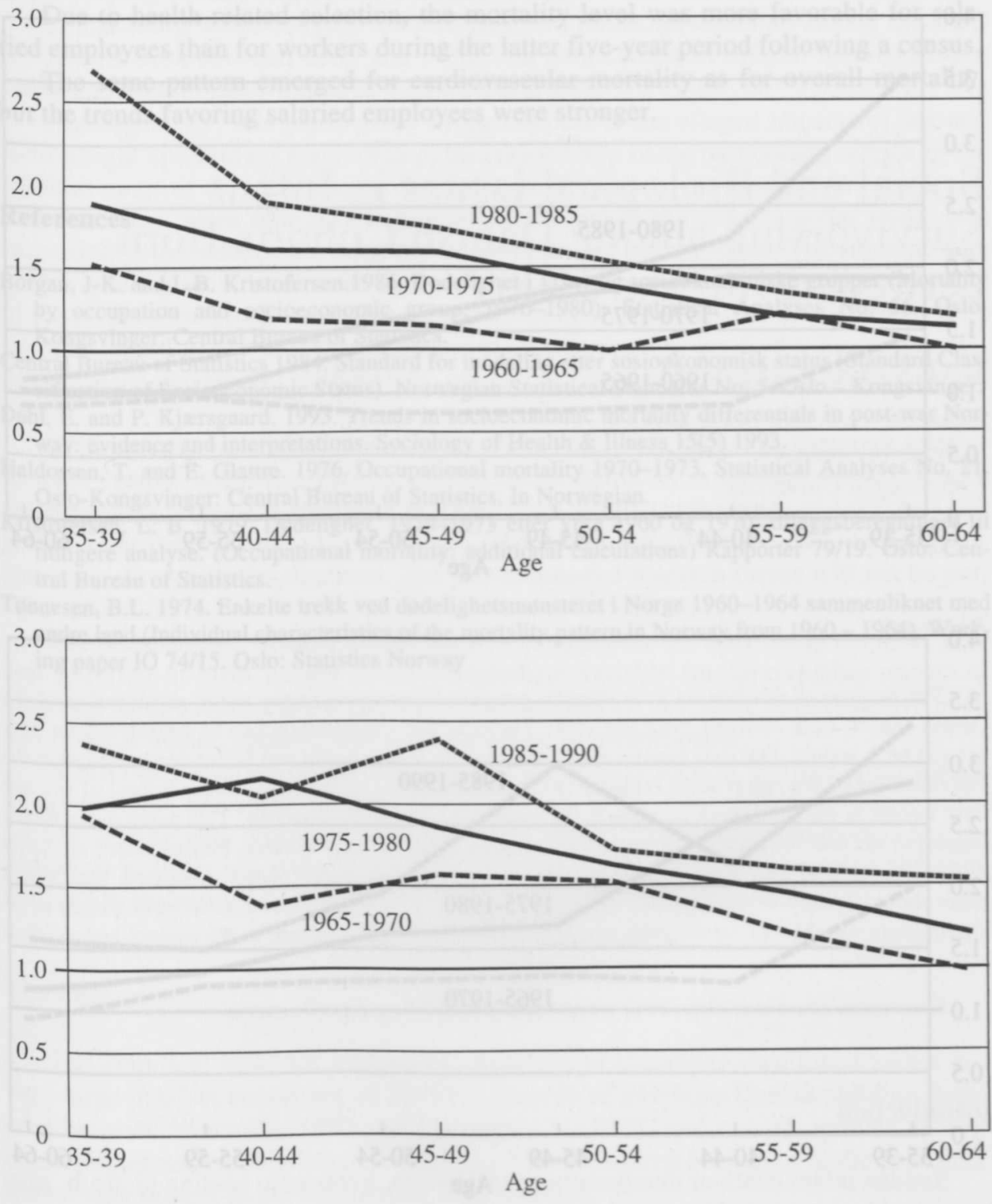

- the second period is more heterogeneous, as it also contains people who have retired or switched to a different socioeconomic status category several years prior to their date of death.

Although the data from the second period are more heterogeneous, there is reason to prefer these data when comparing mortality rates among different socioeconomic groups, as they include people who retired or switched to an easier job due to failing health some years before they died. Another possibility is to group pensioners according to their former socioeconomic status group. 
Fig u r e 2. Ratio of the age-specific mortality from cardiovascular diseases of unskilled workers to that of higher salaried employees in 1960-1990.
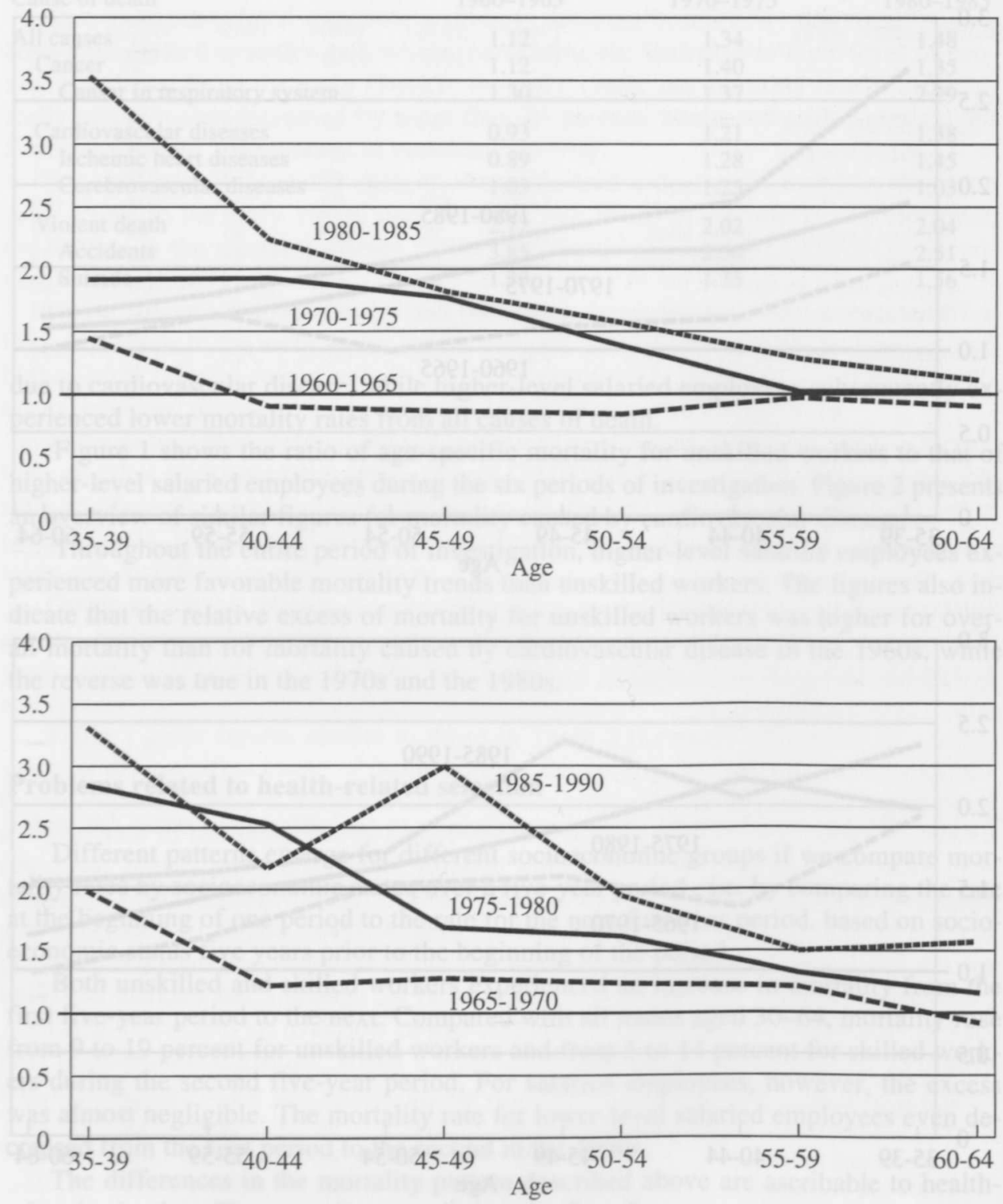

\section{Summary}

The overall mortality rate for males aged 30-64 increased slightly in the $1960 \mathrm{~s}$. A notable decrease was observed after 1970, and the mortality rate was 8 percent lower in the late 1980 s than in the early 1960 s. Owing to a decline in economic activity, a significant decline in mortality was observed for most socioeconomic groups. The strongest decline was observed among salaried employees, the weakest among farmers, fishermen and unskilled workers. This pattern remained constant throughout the entire period of observation.

The period after 1970 is characterized by a substantial decrease in male mortality, especially from cardiovascular disease. It is believed that cardiovascular mortality is 
related to lifestyle. The figures in Table 3 indicate that salaried employees switched to a healthier lifestyle than unskilled workers, farmers, and fishermen.

Due to health-related selection, the mortality level was more favorable for salaried employees than for workers during the latter five-year period following a census.

The same pattern emerged for cardiovascular mortality as for overall mortality, but the trends favoring salaried employees were stronger.

\section{References}

Borgan, J-K. and L.B. Kristofersen.1986. Dodelighet i yrker og sosiookonomiske grupper (Mortality by occupation and socioeconomic group, 1970-1980). Statistical Analyses No. 56. OsloKongsvinger: Central Bureau of Statistics.

Central Bureau of Statistics 1984. Standard for inndeling etter sosioøkonomisk status (Standard Classification of Socioeconomic Status). Norwegian Statistical Standards No. 5. Oslo - Kongsvinger.

Dahl, E. and P. Kjærsgaard. 1993. Trends in socioeconomic mortality differentials in post-war Norway: evidence and interpretations. Sociology of Health \& Illness_15(5) 1993.

Haldorsen, T. and E. Glattre. 1976. Occupational mortality 1970-1973. Statistical Analyses No. 21. Oslo-Kongsvinger: Central Bureau of Statistics. In Norwegian.

Kristofersen, L. B. 1979. Dødelighet. 1970-1973 etter yrke 1960 og 1970: tilleggsberegninger til tidligere analyse. (Occupational mortality: additional calculations) Rapporter 79/19. Oslo: Central Bureau of Statistics.

Tønnesen, B.L. 1974. Enkelte trekk ved dødelighetsmønsteret i Norge 1960-1964 sammenliknet med andre land (Individual characteristics of the mortality pattern in Norway from 1960 - 1964). Working paper IO 74/15. Oslo: Statistics Norway 